\title{
Thermal error of high speed feed system of NC machine tool
}

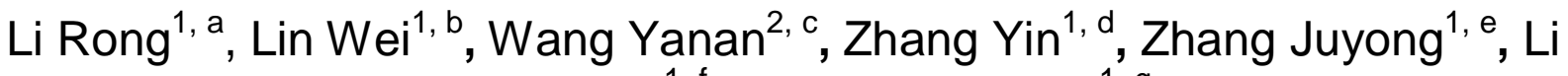 \\ Chunguang ${ }^{1, f}$ and Chen Zhiping ${ }^{1, g}$ \\ ${ }^{1}$ Hangzhou Dianzi University, Hangzhou, China, 310018; \\ ${ }^{2}$ Zhejiang University, Hangzhou, China, 310018
}

alirongjx@hdu.edu.cn, b1305713560@qq.com, ' $1287577260 @ q q . c o m,{ }^{d} 529358477 @ q q . c o m$, èhang_juyong01@163.com, 'lichunguang@hdu.edu.cn, 9lichunguang@hdu.edu.cn

Keywords: Finite element analysis; Thermal characteristics; Thermal error; Thermal compensation Abstract. The increase of the feed speed leads to severe thermal deformation, which seriously affects the positioning accuracy. Therefore, we take the X-ray feed system for machining center as the research object. Then, by analyzing the main heat source and establish a finite element model, the steady-state temperature field is obtained. Finally, we analyze the heat transfer law of the feed system, which provides theoretical guidance for thermal deformation compensation.

\section{Introduction}

The errors of high-speed CNC machine tool have become a key factor influencing machining accuracy and stability. With the increasing of the feed speed, which directly leads to thermal deformation of machine tool structure and positioning error. The research shows that thermal error has become the largest error source of NC machine tool, which accounts for $40 \%$ to $70 \%$ of the total error [1].

As high transmission efficiency and long service life, ball screw feed system has become the mainstream form of high speed feed system. In machine tool feed system, the ball screw pair and support bearing are the main source of heat for the feed system, which is similar to the heating mechanism of the nut, and the frictional heat generated by the support bearing causes thermal deformation of the component [2]. The high speed of the feed system will generate a large amount of frictional heat, and the thermal deformation caused by it will become the main part of positioning error [3]. The feed system plays an extremely important role in the research of CNC machine tools, thus, it will help us to improve the machining accuracy of CNC machine tools by studying the thermal characteristics and thermal error compensation methods [4].

In order to analyze the thermal characteristics of the high-speed feed system, we analyze the main heat source of the ball feed system and get the steady-state temperature distribution of the feed system. Finally, the heat transfer law of the feed system is obtained.

\section{The finite element modeling of feed system}

Positioning accuracy of the feed system of the RL850 machining center is $\pm 0.01 \mathrm{~mm} / 300 \mathrm{~mm}$, the processing speed is $5 \mathrm{~m} / \mathrm{min}$. We take the $X$ direction ball screw feed system as the analysis object and establish the feed system model, the simplified model is shown in Fig.1. To simplify the analysis, we make the following assumptions:

(1) The screw and screw nut are respectively simplified to the equal diameter rod and the corresponding axle sleeve.

(2) The bearings are simplified to bushes, and the heat transfer error caused by the simplified structure can be compensated by the contact thermal conductivity.

(3) Reference to Yovanovich [5] and Mikic [6] thermal contact conductance theoretical model, by predicting and estimating method[7], we take the screw-bearing contact thermal conductivity is $3200 \mathrm{~W} / \mathrm{m}^{2} \cdot{ }^{\circ} \mathrm{C}$, screw nut contact thermal conductivity is $2000 \mathrm{~W} / \mathrm{m}^{2} \cdot{ }^{\circ} \mathrm{C}$, nut-holder contact thermal conductivity is $1800 \mathrm{~W} / \mathrm{m}^{2} \cdot{ }^{\circ} \mathrm{C}$. 


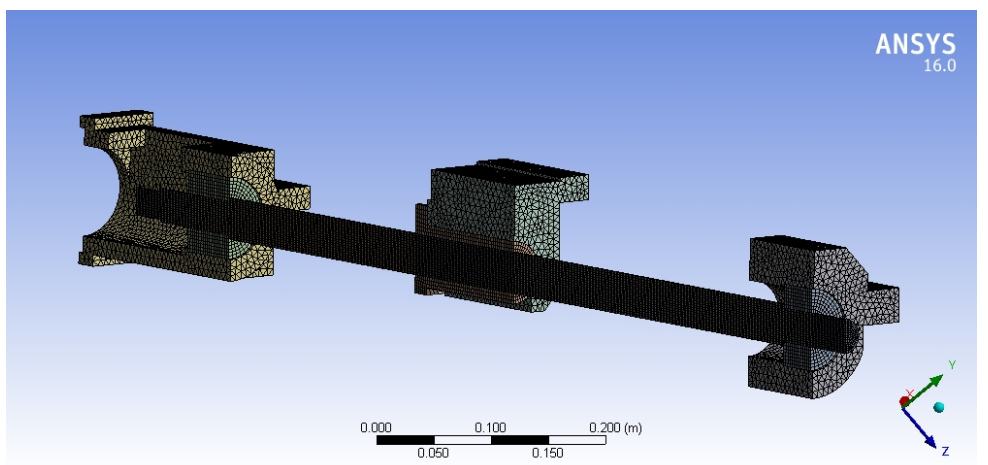

Fig.1 The finite element model of feed system

\section{The thermal analysis of feed system}

In order to achieve the distribution of the main heat source in the feed system, so we need calculate this coefficients such as the heat generation rate of the bearing $h_{1}$, the heat generation rate of ball screw $h_{2}$, forced convection coefficient $h_{\text {force }}$, natural convection coefficient $h_{\text {free }}$, and contact thermal conductivity between contact surfaces.

\section{The heat generation of bearings}

To calculate the heat generation rate of support bearings $Q_{1}(w)$, we need to calculate the calorific value of the bearing and the volume of the bearing $V_{1}\left(m^{3}\right)$ [8]. In generally, the heat generation of the bearing mainly comes from the frictional heat generated by the frictional torque of the bearing, the heat generation can be calculated by the following formula.

$$
Q_{1}=1.047 \times 10^{-4} \mathrm{nM}
$$

In Eq. (1), $\mathrm{n}$ is the rotational speed ( $\mathrm{rpm}), M$ is the total friction torque ( $\left.\mathrm{N}^{*} \mathrm{~mm}\right)$.

The heat generation rate of the bearing can be obtained by the following formula.

$$
h_{1}=\frac{Q_{1}}{V_{1}}
$$

In Eq. (2), $\mathrm{Q}$ is the heat generation (W), $V_{1}$ is the volume of the bearing $\left(\mathrm{m}^{3}\right)$.

\section{The heat generation of screw nut}

The working mechanism of the screw nut is similar to the bearing [9], so the heat generation $Q_{2}$ can still be given by Eq. (1). The total friction torque can be calculated by Eq. (3).

$$
M=M_{1}+M_{2}
$$

Where, $M_{1}$ represents the driving torque of the screw, $M_{2}$ represents the ball screw resistance torque, and can be calculated by Eq. (5).

$$
\begin{gathered}
M_{1}=\frac{F_{a} P_{h}}{2 \pi \eta} \\
M_{2}=\frac{F_{p} P_{h}}{2 \pi \eta}\left(1-\eta^{2}\right)
\end{gathered}
$$

The calculation of convection coefficient

There are two kinds of convection heat transfer between the ball screw system and the outside air, which include forced convection heat exchange with the air and natural convection heat transfer between other parts and the outside air [10].

When the screw rotates at a high speed, the air flows along the surface of the screw at a certain speed. The movement of air along the axis of rotation and the flow of air along the surface of the plate are very similar. Therefore, the formula for calculating the convection coefficient of air along the plate can be used to derive the heat convection coefficient of the screw when rotating with the air. 


$$
h_{\text {force }}=0.664 \frac{\lambda}{l} R_{e}^{1 / 2} P_{r}^{1 / 3}
$$

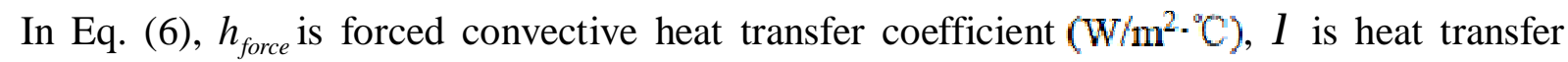
coefficient of air $\left(\mathrm{W} / \mathrm{mm}^{\circ} \mathrm{C}\right), l$ is the feature length $(\mathrm{m})$, Re is Reynolds number.

If a heated ball screw system were exposed to ambient air, the screw surface and the surrounding air will exchange heat by convection. This phenomenon is free-convection, which can be defined as

$$
h_{\text {free }}=\frac{\lambda C\left(G r[\operatorname{Pr})^{n}\right.}{l}
$$

Where the values of constants $\mathrm{C}$ and $\mathrm{n}$ specified for each case, depending on the heat source and fluid flow properties, $G r$ is Grashof number, Pr is Prandtl number.

The analysis of steady temperature field

After the boundary conditions are determined, the corresponding finite element model is loaded respectively, and setting the ambient temperature is $20^{\circ} \mathrm{C}$, thus the steady state temperature field of the system are obtained.

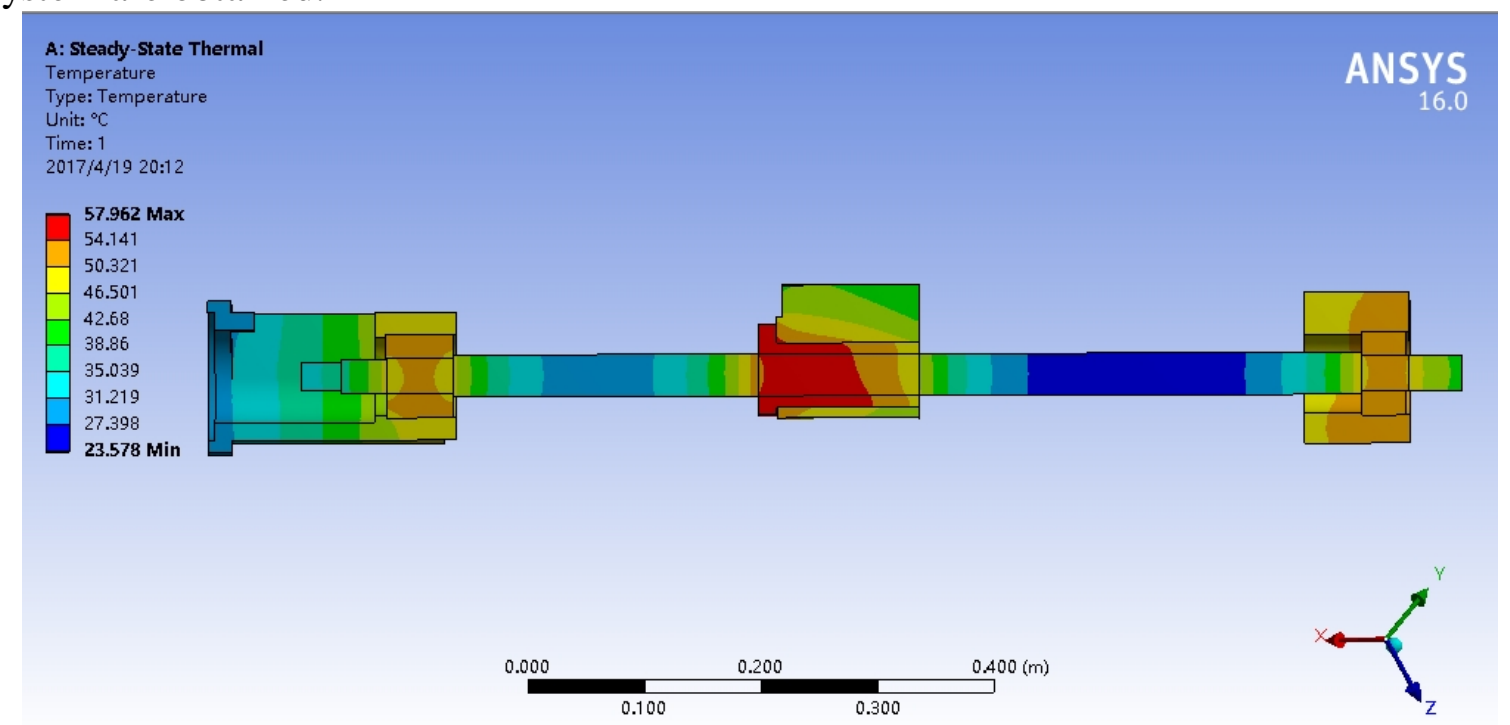

Fig. 2 The whole steady-state temperature field of feed system

From the temperature distribution diagram of the feed system, it is known that the ball screw pair and the bearing are the main heating sources of the feed system. The highest steady-state temperature of the ball screw system is $57.962^{\circ} \mathrm{C}$, which occurs in the screw nut pair. The minimum temperature is $23.578^{\circ} \mathrm{C}$, which occurs between the nut pair and the rear bearing. The temperature of the front and rear bearings reaches to $50.321^{\circ} \mathrm{C}$. The main heating area of the screw is respectively installed in the friction area with the nut and bearings. In this steady-state temperature field, the highest temperature of the nut is $57.962^{\circ} \mathrm{C}$, and the temperature gradually decreases toward both sides along the axial direction.

From the temperature condition of the feed system described, it is known that the heating capacity of the screw nut pair is the most obvious.

\section{Conclusion}

The X-ray feed system of machining center is taken as the research object in this paper, we have analyzed the thermal characteristics of bearings and nuts, and determine the main heat exchange type of the screw system during the work process.

Firstly, we simplify the feed system and establish a finite element model. Next, through the material properties of the components, we determine thermal conductivity between parts at each contact interface. Then, we calculate the parameters such as the heat generation of the screw nut, the heat generation of the bearing, and the convection coefficient between the component and the 
external environment. Finally, we calculate the steady-state temperature distribution of the feed system by using finite element.

The heat transfer law of the feed system is obtained, which provides theoretical guidance for the thermal deformation compensation.

\section{Acknowledgements}

This work was financially supported by the Zhejiang Province Commonweal Projects of China (2015C31077).

\section{References}

[1] Fu JianZhong, Yao Xinyu, He Yong, et al. The development of thermal error compensation technology for CNC machine tools [J]. Aviation Manufacturing Technology, 2010, (4), 64-66.

[2] O. Horejs. Thermo-mechanical Model of Ball Screws with Non-steady Heat Sources [J] Thermal issues in Emerging Technologies, 2007, (6):17-19.

[3] Yang Jinbin, Yang Weiping, Huang Guiying. Ball screw thermal displacement suppression measures [J]. Manufacturing Technology and Machine Tools, 2006, (8):109-110.

[4] Guo Ce, Sun Qinghong. High-speed high-precision CNC lathe spindle thermal analysis and thermal deformation calculation [J]. Journal of Southeast University: Natural Science Edition , 2007,(2):37-39.

[5] Mikic. B. B. Thermal contact conductance, theoretical considerations [J]. International journal of Heat and Mass Transfer, 1974, 17:205-214.

[6] Zhao Haitao , Yang Jianguo. Simulation of thermal behavior of a CNC machine tool spindle [J]. International Journal of Machine Tools and Manufacture, 2007, 47:1003-1010.

[7] He Zhen. Thermal characteristics analysis of machine ball screw system and its thermal deformation compensation [D]. Chengdu: Xi'an Jiaotong University, 2009.

[8] Zhang Gang. Development and experimental analysis of ball screw pair friction torque measuring instrument [D]. Shandong: Shandong University, 2007.

[9] Liu Leping, Ma Yuan, Zhong Mingdong. Research on Thermal Characteristics of High Speed and High Precision CNC Lathe Feeding System [J]. Machine Tool \& Hydraulics, 2012, (3):36-39.

[10]Wan Changsen. Analysis Method of Rolling Bearing [M]. Machinery Industry Press, 1985:15-81. 